\title{
Implementing A Risk Management Framework In Developing Markets
}

Joseph Chisasa, University of South Africa-Pretoria, South Africa Jacobus Young, University of South Africa-Pretoria, South Africa

\begin{abstract}
This article assesses the status of operational risk management of banks in developing markets in the context of Basel II. The aim of the article is to determine the extent to which risk management staff is prepared to implement a risk management framework in line with international best practice. An African commercial bank was examined using survey data collected in July 2010 from 22 employees. The data were analysed using descriptive statistics. Results obtained indicate knowledge gaps in collecting risk data and the application of risk models as limitations to the implementation of the framework. The results support the commitment of more time and financial resources in up-skilling staff if banks in developing markets are to comply with regulatory requirements as recommended by the Basel Accord.
\end{abstract}

Keywords: Operational Risk; Risk Management Framework; Developing Markets; Basel II; Regulatory Capital

\section{INTRODUCTION}

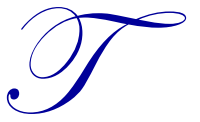

he management of banking institutions has gathered momentum since the 2008 global financial crisis which started in the United States of America before spreading to the rest of the world. An analysis of the effects of the crisis revealed that the need for management of credit, market and operational risk remains critical if investor confidence is to be restored in the global financial markets. In 2006, the Basel Committee on Banking Supervision introduced the Basel II Accord, which contained measures meant to enhance risk management for banks. In particular, the Accord recommended risk measurement methodologies which would capture operational risk into the calculation of the capital charge for the banks' risk exposures. Operational risk is one of loss resulting from inadequate or failed internal processes, people and systems, or from external events. Typically, operational risk emanates from fraudulent activities, natural disasters, human errors or omissions, use of highly automated technology, the growth of e-commerce, large-scale mergers and acquisitions, and the emergence of banks as very large volume service providers.

For a long time, operational risk was not considered a major risk, with emphasis being placed on credit and market risks. Operational risk has proved to be an important cause of huge financial losses in banks and financial institutions with leading cases including losses suffered by Société Générale of $€ 7.1$ billion, Barings Bank (1995,\$1.3 bn), Allfirst (2002, \$750 mn) and NAB (2004, A \$360 mn) (Bodla \& Verma, 2008:63). In the Basel II Accord, three main methodologies have been proposed for calculating the operational risk regulatory capital - the Basic Indicator Approach (BIA), the Standardised Approach (SA) and the Advanced Measurement Approach (AMA). The application of these methodologies has posed data-collection and modelling challenges to risk management personnel. This has led to slow progress in the total implementation of the advanced methods of managing operational risk in most banks and financial institutions in developing markets.

Studies have been conducted to reinforce the importance of paying attention to operational risk in spite of its measurement challenges (Alexander, 2005; Janakiraman, 2008; Jimenez-Rodriguez, Feria-Rodriguez \& MartinMarin, 2009). Up to now, the focus of financial econometric research has been on the assessment of market and credit risk, with limited work done to study operational risk. Unlike previous studies, it is the objective of this article to explain the current state of operational risk management in developing economies. 
The article hinges on the challenges encountered by risk management personnel when implementing an operational risk management framework. In order to explain the prevailing situation, a survey was conducted among risk management staff at a Tanzanian commercial bank. A semi-structured questionnaire was used to collect data which was analysed using the Statistical Package for the Social Sciences (SPSS). The article acknowledges the work done by Van Niekerk, Levin and Geldenhuys (2011). Using a qualitative, interpretive research methodology, they argued that the successful implementation of a risk management framework in Tanzania should take into account socio-cultural factors, demonstrated as part of an integration activity, in order to successfully implement a risk management framework. The findings of Van Niekerk et al (2011) are consistent with those of Avery, Baradwaj and Singer (2008:73) who confirm Hofstede's explanation of the cultural difference dimension when making an investment decision in another country with different societal and cultural values.

The emphasis in this article is on the use of the Advanced Measurement Approach (AMA) as it is the most sophisticated of the three above-mentioned methods. It highlights the challenges encountered by banks in the total implementation of an operational risk management framework. This article contributes by highlighting the lack of expertise of risk management personnel of banks and financial institutions in applying the AMA. This hinders the successful implementation of an operational risk management framework. It is recommended that banks train their risk management personnel on the application of the AMA. Banks and financial institutions need to be proactive in managing operational risk as its level of sophistication continues to grow from strength to strength.

\section{LITERATURE REVIEW}

To date, available literature has concentrated on the definition and modelling of operational risk (Jobst, 2007; Jimenez-Rodriguez, Feria-Rodriguez \& Martin-Marin, 2009). In this section, the reviewed literature on the generic operational risk management framework and the measurement methodologies recommended by the Basel Committee are explored. Some of the impediments to the successful implementation of the framework are also put forth.

\section{The Operational Risk Management Framework}

The operational risk management framework is best explained by defining operational risk. The Basel II Committee (Basel Committee on Banking Supervision, 2004) defines operational risk as "the risk of loss resulting from inadequate or failed internal processes, people and systems or from external events. This definition includes legal risk, but excludes strategic and reputational risk." The definition is a causative one, in as much as it talks about the causes of operational risk - people, policies, procedures and systems and external events. Young (2006) concurs with this definition and so do Lubbe and Snyman (2009). According to the Basel Accord, the Committee needs further collaboration with the industry to define operational risk (Basel Committee on Banking Supervision, 2004:94). This suggests that the definition of operational risk is by no means conclusive at this stage and the need for further consultation is apparent. Notwithstanding this fact, the available definition provides a sufficient point of departure for determining the roadmap for managing operational risk.

The Basel definition approaches risk from an operations viewpoint, rather than from the outcome of operational risk. Operational risk may materialise directly, as in the case of, for example, wire transfer (transfer of funds to the wrong person) or could result indirectly as a credit or market loss. Given the close linkage of operational risk with other risk types, it is very important for banks to first have a clear understanding of the concept of operational risk before designing the operational risk measurement and management framework. Figure 1 is a schematic presentation of the operational risk management framework.

\section{The Risk Management Process}

Matis (2009) offers a simplified operational risk management process as one that begins with risk identification, evaluation, monitoring and management. 


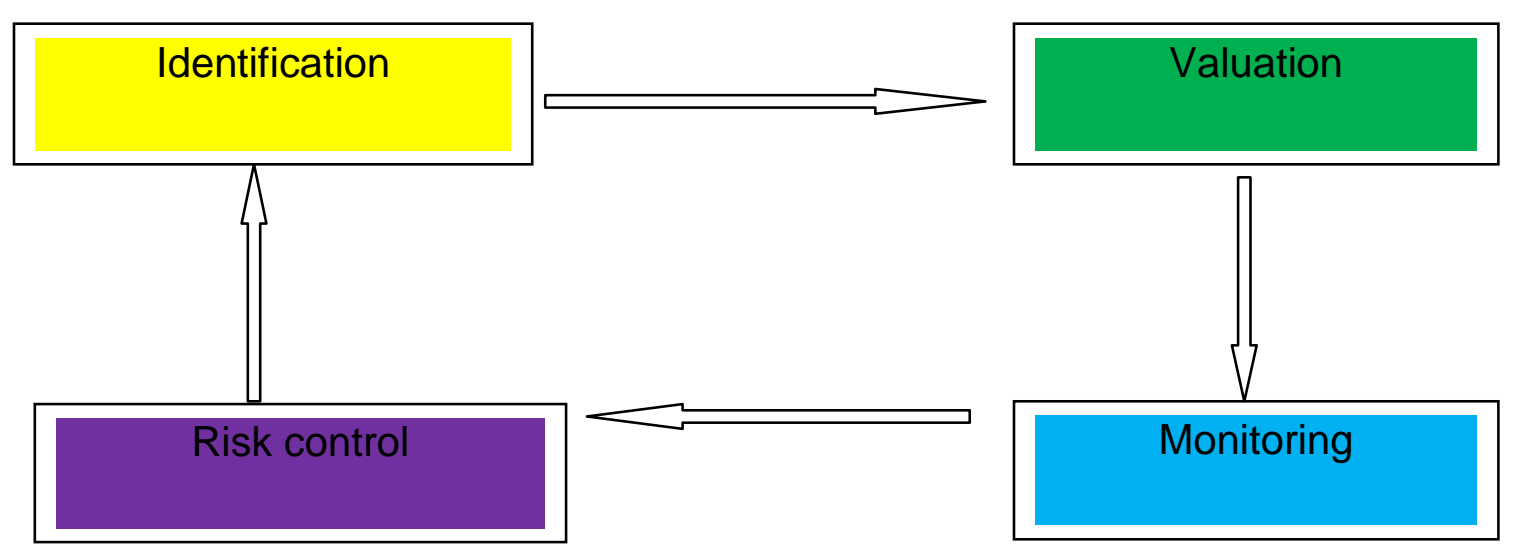

Figure 1: Operational Risk Management Process

Source: Author

The first step in the risk management process is to identify the risk to which the bank is exposed. The identified risk will form the basis for determining viable systems for monitoring and controlling operational risk. The estimation and valuation of the losses stemming from the identified risks is the next step. This step involves the use of recorded loss data from existing databases regarding operational risk losses, calculating and analysing some key ratios. The valuation of operational risk focuses on the correlations of this risk with other risks affecting the bank as this risk may determine the development of other risks, mainly the credit risk, market risk and reputation risk (Matis, 2009:595). After identifying and valuating the risks that affect the business' activities, the risk owners should take appropriate measures to prevent manifestation of the risk. This is the monitoring stage. Risk control is the last stage in the risk management process and involves management's decision on how to deal with the identified risks. The bank may decide upon decreasing the risks by instituting sufficient control measures, which may include training the personnel or clients, transferring the risks to third parties, and eliminating the risks by closing the activity. To mitigate the operational risk inherent in their businesses, risk owners transfer a part of the operational risks with which they are faced. They do this by taking insurance policies regarding some types of events generating operational risk. Thus far, the operational risk management framework has been presented. The following section discusses the Basel II Accord which is the guiding blueprint for all banking and financial services practitioners involved in risk management.

\section{The Basel II Capital Accord (Basel II)}

Basel II gives banks four options that they can use to calculate regulatory capital for operational risk. Each of these options requires an underlying risk measurement and management system, with increasing complexity and more refined capital calculations as one moves from the most basic to the more advanced approaches. The most advanced and complex option under Basel II is AMA. This approach allows a bank to calculate its regulatory capital charge (using internal models) based on internal risk variables and profiles and not on exposure proxies like gross income. Empirical work by Teply, Sekhri and Chalupka (2010:83) has demonstrated that when using the AMA, rather than the Basic Indicator Approach (BIA) used in Basel II, the researched bank might save approximately 67\% of its capital requirement on operational risk. In a similar study, Hassan and Aziz (2008:47) examined the risk management processes of a Malaysian bank through interviews, documents and physical observation. Results showed the implementation of a risk management programme and a record of how the bank manages its operational risk. This is the only risk-sensitive approach for operational risk allowed and described in Basel II.

While the major banks in advanced countries have made considerable progress in the area of operational risk management, the awareness of operational risk is a recent phenomenon in the emerging markets (Janakiraman, 2008). For this reason, it is important to gain an insight into the reasons for the slow response to a type of risk that has already proved costly. 


\section{Challenges Associated With The Implementation Of The Operational Risk Management Framework}

During the last decade or so, financial institutions have been modifying both their products and internal processes at a rapid pace, leading to an increased exposure to operational risk. Consequently, supervisors of financial institutions have expressed increased concerns on institutions' potential exposure to operational risk, and future institutions could be required to enhance their risk management capabilities with respect to their operational processes. Although well-defined tools and techniques are used for the assessment and modelling of financial risks inherent in financial products, comparable approaches are still in a developing stage on the operational risk side. According to Di Renzo et al (2007), up to now no international agreement has been reached on how to actually implement or assess compliance with those requirements. To counter this setback, a model operational risk management framework, as explained below, is suggested for banks.

Three fundamental aspects underpin the overall effectiveness of an organisation and also influence the risk management framework. The business strategy determines how the organisation will compete in a specific business environment and to what risks it will be exposed. The organisational structure links management structures to roles and responsibilities for the purpose of achieving business objectives and establishing risk management activities. Incentives and compensation provide rewards for all the role-players, such as key personnel and shareholders (Schwartz \& Smith, 1997:411).

The way in which an organisation is structured to undertake risk management is of utmost importance. A central theme regarding the different approaches toward an organisational structure for risk management is the recognition of a top-down approach to the process. Unless risk management is fully endorsed and actively supported by the board and senior management of an organisation as an integral part of the way the organisation is managed, it cannot be effective. The board of directors and senior management should be actively involved in overseeing the operational risk management framework. Thus, the board needs to clearly formulate the organisation's attitude toward risk and the assignment of responsibilities for assessing and controlling risks. The responsibility for the approval and implementation of the risk policy also lies with the board of directors who empower the executive committee and the chief risk officer to enforce the policy. The business unit risk committees are responsible for the implementation of procedures to manage the risks. Risk control is a bottom-up function but should involve all levels of management. For example, at the lower levels, risk control measures are implemented, while at the higher level of management, risk information is used to make decisions on how to deal with the risk exposures (Young, 2006).

It is essential that the risk management function be established independently of the business operations and operated as a controlling or monitoring function. This will allow risk management to provide assurance to senior management and the board that the organisation is assessing its risk effectively and complying with its own risk management policies.

Table 1 lists some typical types of operational risks. It is clear from this table that some risks are difficult to quantify (like 'Incompetency' under 'People risk') whereas others lend themselves much more easily to quantification (for instance, 'Execution error' under 'Transaction risk') (Crouchy, Galai \& Mark, 2000). Embrechts, Furrer and Kaufman (2003) added a column to this table indicating whether a certain risk typically creates repetitive and non-repetitive losses. They observe that sometimes the distinction between 'repetitive' and 'non-repetitive' is not quite clear. If there is ambiguity (according to their judgment), they use the notion 'yes (no)', for example, to indicate that this type of risk is mostly repetitive. 
Table 1: Types Of Operational Risks

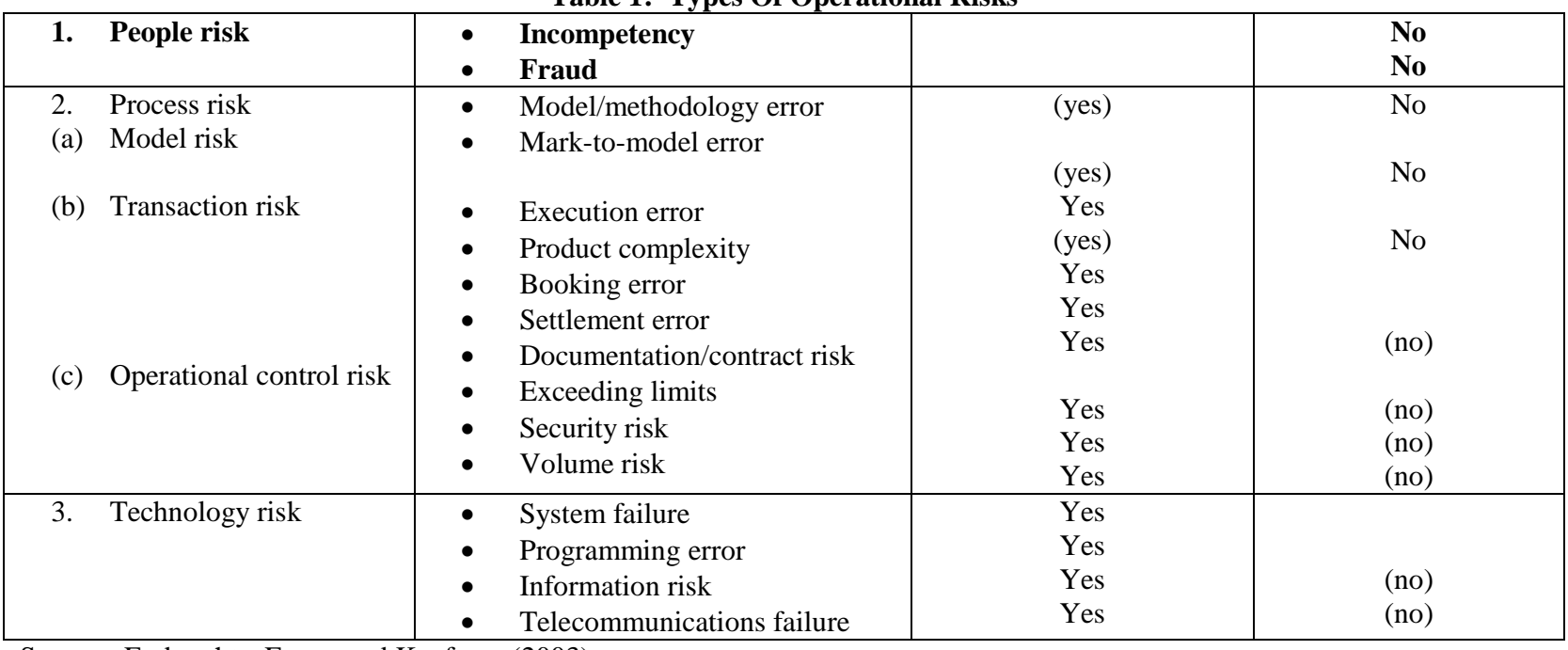

Source: Embrechts, Furrer and Kaufman (2003)

The Basel II Accord has been hailed as an appropriate prescription for managing risk in banks. Contrary to the benefits articulated by Teply et al (2010:83) and Hassan et al (2008:47), Moosa (2008) argues that AMA is problematic. Conducting a cost-benefit-analysis of AMA, Moosa contends that "the implementation of AMA, if at all possible, is rather difficult and expensive, particularly because there is more reason to believe that the output (the estimated capital charge) would be of suspicious value". While assessing the impact of Basel II in Bangladesh, Akhtaruzzaman (2009:52) noted:

The single largest cost of implementing Basel II is the IT costs. The required capital expenditure would be, by far, greater than small banks could bear. There is an unavailability of trained manpower for risk management and audits. Many countries have a paucity of skilled manpower in this area. The training cost is another factor in implementation, especially in state-owned banks in developing economies where the majority of the workforce requires training.

Such problems pose challenges to the implementation of a risk management framework.

In the next section, the data collection method is explained and the data analysis technique is outlined.

\section{DATA COLLECTION}

The objective of the research on which this article is based was to determine the constraints faced by risk management personnel in implementing the operational risk management framework for banks and financial institutions in developing economies. To achieve this objective, a case study approach was used. Data were collected from selected employees of an African bank whose holding company is in Africa. Observing research ethics, the name of the Tanzanian bank was withheld and is referred to herein as the Bank. Permission to collect data from the Bank was granted by the parent company. The parent company has already moved to the AMA methodology in line with Basel II recommendations. In line with the holding company policy, the Bank is also applying the AMA. The questionnaire tested the competency levels of risk personnel with respect to the AMA.

The respondents were selected using purposive sampling techniques. This approach was chosen in order to capture the input of personnel from all levels of the risk structures. As this was a project commissioned by the holding company, access to the respondents was facilitated by management of the subsidiary in Tanzania. A pilot test for robustness and reliability of the research instrument was used on one of the members of senior management from the Bank. The questionnaire was adjusted with the guidance of the respondent to suit the target respondents. Twenty-two responses were received. The data were captured and analysed using the Statistical Package for Social 
Sciences (SPSS). Questions without complete answers were excluded from the analysis to enhance the accuracy of the results. Descriptive statistics were applied to analyse the data.

\section{RESULTS, FINDINGS AND RECOMMENDATIONS}

Much of the work done in operational risk in banks can be traced to the regulations under the new capital adequacy framework and is closely linked to the implementation of Basel II. However, the Accord itself states that operational risk management should be closely linked to the business strategy of the bank and should not end up as a mere compliance issue. It is in this context that a case study was carried out to assess the position of a specific Tanzanian bank (called the Bank in this article) in the area of operational risk. The case study was administered by means of a semi-structured questionnaire containing 33 questions. The written responses to the questionnaires were received from a total of 22 participants between 25 and 31 July, 2010. The thematic results of the analysed data are detailed next:

\section{Theme 1: Organisational Set-Up For Operational Risk}

Most of the employees had a clear understanding of the organisational set-up for operational risk (see Figure 2) which is managed as an independent function as confirmed by $95 \%$ of the respondents. Respondents stated that the organisational chart for operational risk had a large external influence, such as the parent company.

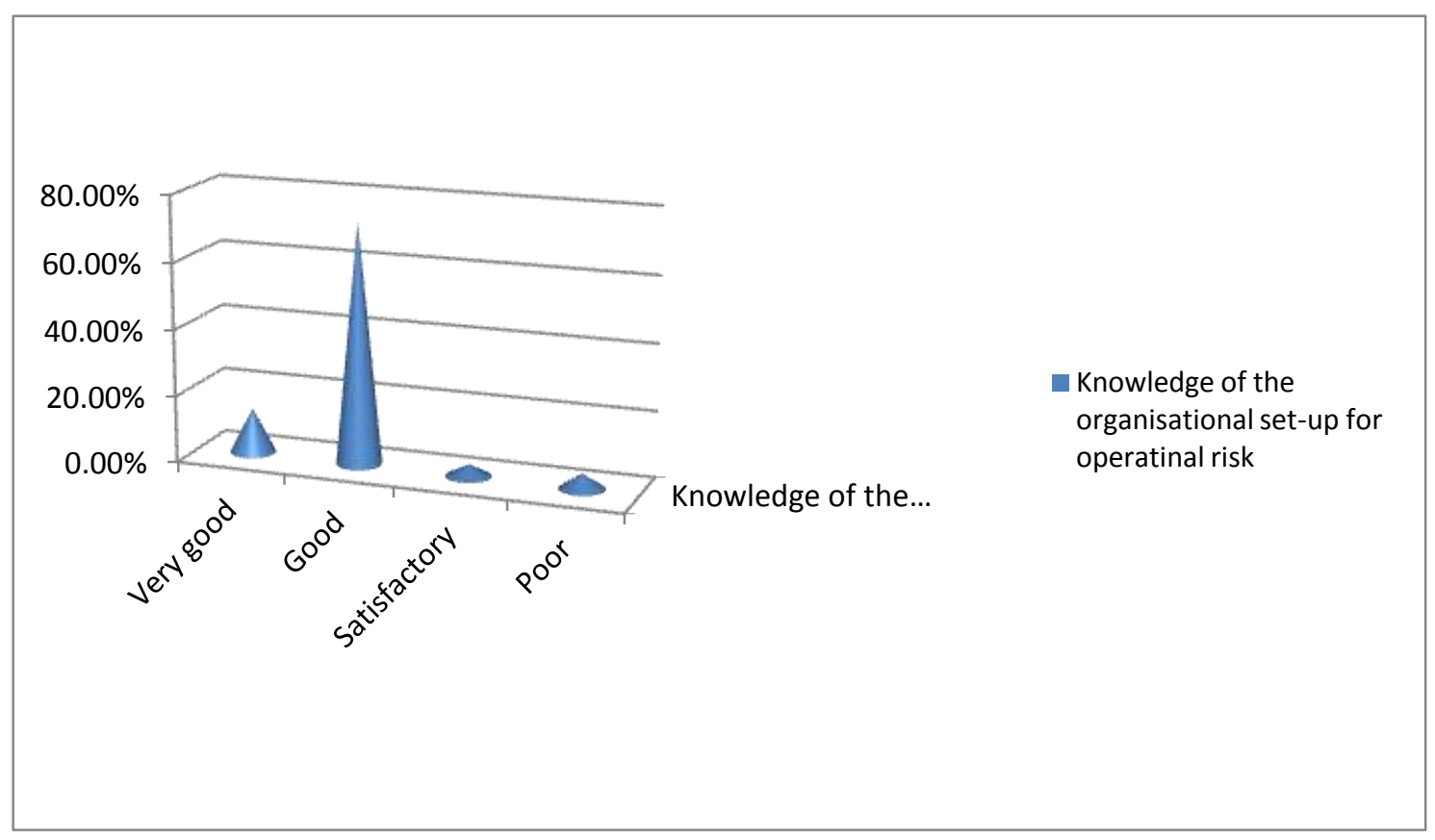

Figure 2: Knowledge Of The Organisational Set-Up For Operational Risk

\section{Theme 2: Risk Assessment}

Respondents were asked to identify types of operational risk for banks in terms of impact on the bank's business. An accurate analysis could not be achieved due to some missing responses/data from the questionnaires. A significant number stated that they use Key Risk Indicators (KRIs) and inspection/audit report findings to assess operational risk.

\section{Theme 3: Monitoring Operational Risk}

Respondents indicated that they use the following tools to monitor operational risk:

- $\quad$ Self-assessment

- $\quad$ KRIs 
- Inspection/audit report findings

- Loss data

While the above-mentioned risk monitoring tools were cited across respondents, most of them indicated that they use KRIs and findings from audit/inspection reports (see Table 2). Respondents were asked how often they monitor operational risk and it was observed from the responses that it is monitored monthly and quarterly.

Table 2: Tools Used For Monitoring Operational Risk

\begin{tabular}{|l|c|}
\hline Type Of Management Information Used & Level Of Utilisation (\%) \\
\hline Audit reports & 6.3 \\
\hline Principal risk reports & 18.8 \\
\hline Circulars & 12.5 \\
\hline DRACA & 6.3 \\
\hline KRI reports and daily management information alerts (sanctions) & 18.8 \\
\hline RCA and principal reports & 6.3 \\
\hline Audit reports and circulars & 6.3 \\
\hline Principal risk reports, KRI and RCA & 6.3 \\
\hline KRI reports, & 6.3 \\
\hline All & 6.3 \\
\hline
\end{tabular}

All respondents indicated knowledge of the presence of a business continuity plan which has been tested in the last 12 months.

\section{Theme 4: Operational Risk And Internal Audit}

Respondents were asked about the linkage between internal audit and the operational risk management process. It was observed that there is a moderate to full relationship (see Figure 3), thus the Bank is making use of the internal audit inputs in the management of operational risk. Risk-based internal audit has emerged as one of the important tools in the operational risk framework of banks. While this relationship is beneficial and complementary to the aggregate business position, the operational risk management function should remain autonomous. It should also be subjected to a periodic audit to ensure that it upholds ethical and effective risk management practices.

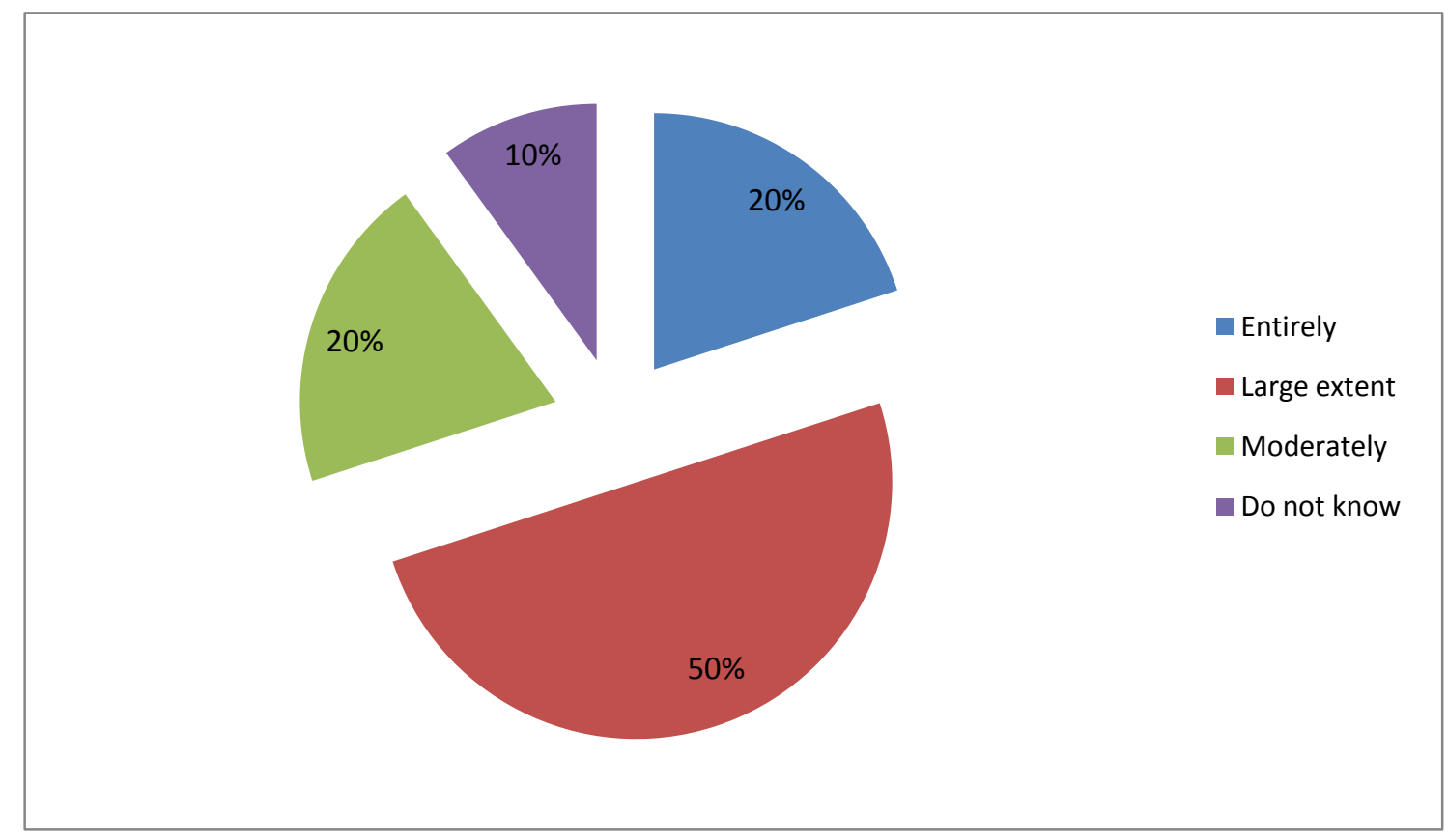

Figure 3: Involvement Of Internal Audit In Operational Risk Management 


\section{Theme 5: Policy Formulation And Strategic Approach}

Employees were asked to respond to a variety of questions on the subject; for example, whether a boardapproved policy was in place, whether external help had been sought to draft the policy document, and whether the policy detailed various aspects such as definitional issues. The Bank has an internally-generated policy. However, some of the respondents (22\%) reported that external assistance had been sought from consultants. Definitional issues on operational risks were reported to be adequately addressed by the Bank. On the application of the advanced approaches, such as the Advanced Measurement Approach and the Basic Indicator Approach, a significant number of respondents (55\%) left some questions unanswered. Of those who did not respond, $64 \%$ occupy supervisory to managerial positions while the remainder are clerical staff. It is also noteworthy that all respondents in the managerial rankings who did not respond to questions under this theme have tertiary qualifications, most of which are at postgraduate level.

Lack of regulatory clarity and the absence of internal and external loss data were reported as significant/highly significant obstacles in the implementation of the operational risk management framework. The extent to which the Bank uses tools, such as loss event database, risk and control self-assessment, KRIs, scenarios and external loss data, could not be accurately determined. A sizeable number of the respondents did not give feedback on the application of these operational risk management tools. This seems to impair the accuracy of the results obtained. Internal data and internal control factors/KRIs, though not significant, were found to be the methods used for measuring operational risk. Respondents were asked for factors that drive operational risk. Key factors identified are the Basel II guidelines and natural disasters/terrorism. Others did not respond to this question.

\section{Theme 6: Capital Allocation For Operational Risk And Implementation Of The Basel Framework}

The majority of the respondents were positive about the effectiveness of the Basel II Accord. However, non-standardisation of models/modelling difficulties, insufficient data, and difficulty in gathering external data were listed by all respondents as obstacles in the implementation of the Advanced Measurement Approach. Lack of regulatory clarity, lack of expertise, difficulty in gathering external data, integrating quantitative and qualitative factors, and lack of technological support were identified as other limitations in designing and implementing an operational risk framework. These findings are consistent with those of Bodla et al (2008:84) who posit that the task of identification and assessment of operational risk (self risk assessment exercise) is based on the experience of bankers (in India).

\section{Synthesis Of Results}

The results discussed above show that the Bank has embraced AMA. However, some elements of the risk management framework remain partially implemented. The concluding remarks that follow present reasons for partial implementation.

\section{CONCLUSION AND RECOMMENDATIONS}

The aim of this article was to determine the adequacy of risk management competencies of the manpower of banks in developing countries. A case study approach using a Tanzanian bank (called the Bank in this article) was used to gather data in July 2010. The results indicate that an operational risk management framework is in place. However, there are some challenges that need intervention which are summarised below.

While some respondents reported that risk monitoring is done monthly, others indicated that they do it quarterly. There is a need to harmonise the risk monitoring function across the business in order to achieve consistency. Evidence suggests that the operational risk management framework is implemented inconsistently across the business. Similarly, management needs to keep an accurate record of loss data at all times. Such data are essential when modelling operational risk. Its unavailability is testimony of the inability of the staff to collate the data. 
The fact that a majority of the respondents did not give feedback on the factors driving operational risk suggests a knowledge gap. A lack of knowledge of the Bank's risk management framework is also evident among risk management personnel. Evidence of this is the varied responses on the measurement techniques of operational risk, such as internal control factors/KRIs, scenario analysis, and internal and external data. Respondents identified regulatory clarity as a significant obstacle in the implementation of the operational risk management framework. This exposes the Bank to a wide range of litigations due to staff incompetence. Training is therefore recommended to bridge this gap and improve the mitigation of risk.

It is evident from the results of the research that there is still much more to be done and that the Bank needs to devote time and resources in order to implement AMA. The study has unearthed some internal operational shortcomings within the Bank's effort to manage operational risk effectively. There are disparities across risk personnel in the level of knowledge of the implementation of the operational risk management framework. It is recommended that an appropriate training programme be put in place to up-skill personnel in risk management. The acquired skills will enhance better implementation of the operational risk management framework. This study excluded the investigation of the presence or absence of an enterprise-wide risk management framework within the Bank.

We are aware of the shortcomings in the research and that it can be improved in a number of ways. Firstly, a similar study can be conducted using a larger sample. Data used in this article were limited to that drawn from employees of the Bank. This can be extended to other banks in Tanzania and Africa. Secondly, further studies can be conducted on modelling capital requirements for operational risk in African banks. The findings will be useful to other banks to benchmark their risk management capacity in terms of the Advanced Measurement approach. Based on results drawn from this study, it is recommended that further research be conducted to determine whether an enterprise-wide risk management framework is already in place and the extent to which it is embedded.

\section{AUTHOR INFORMATION}

Mr. Joseph Chisasa is a Senior Lecturer in the Department of Finance, Risk Management and Banking of the University of South Africa. He holds a Master of Science Degree in Finance and Investment and a Bachelor of Commerce Degree in Banking (Honours). He is a Certified Associate of the Institute of Bankers of South Africa, Associate Member of the Institute of Bankers of Zimbabwe and an Associate Member of the Institute of Credit Management of South Africa. He has published in the International Business and Economics Research Journal. His research interests are in banking and credit risk management. E-mail: Chisaj@unisa.ac.za (Corresponding author)

Dr. Jacobus Young is a Professor of Banking and Risk Management in the Department of Finance, Risk Management and Banking of the University of South Africa. He has published in recognized national and international journals. His research interests are in corporate governance and operational risk management. Address: University of South Africa, PO Box 392, Pretoria 0003, South Africa. E-mail: youngj@unisa.ac.za

\section{REFERENCES}

1. Akhtaruzzaman, Md. (2009). Potential impact of Basel II in developing economies: experiment on Bangladesh. International Research Journal of Finance and Economics, 23:46-61.

2. Alexander, C. (2005). The present and future of financial risk management. Journal of Financial Econometrics, 2005, 5(1):3-25.

3. Avery, A.E., Baradwaj, B.G. \& Singer, D.D. (2008). An examination of Hofstede's cultural factors in explaining differences in Citibank International Retail Banking web sites. Journal of Business and Economics Studies, 14(2):73-90.

4. Basel Committee on Banking Supervision (2004), "International Convergence of Capital Measurement and Capital Standards: A Revised Framework", BIS, June, Switzerland, (Updated in June, 2006).

5. Bodla, B.S. \& Verma, R. (2008). Operational risk management framework at banks in India. The Icfai University Journal of Financial Risk Management, 4:63-85.

6. Crouchy, C., Galai, D., and Mark, R. (2000). Risk Management. McGraw-Hill, New York. 
7. Di Renzo B., Hillairet M., Picard M., Rifaut A., Bernard C., Hagen D., Maar P., Reinard D. (2007). Operational risk management in financial institutions: Process assessment in concordance with Basel II. Software Process Improvement and Practice, 12:321-330.

8. $\quad$ Embrechts P., Furrer H. \& Kaufman R. (2003), Quantifying Regulatory Capital for Operational Risk.

9. Hassan, S.S.S.A., \& Aziz, R. (2008). Managing operational risks in a bank: Applied research in Malaysia. Asia-Pacific Management Accounting Journal, 3(1):47-65.

10. Janakiraman, U. (2008), Operational Risk Management in Indian Banks in the Context of Basel II: A Survey of the State of Preparedness and Challenges in Developing the Framework. Asia Pacific Journal of Finance and Banking Research, 2(2):26-44.

11. Jimenez-Rodriguez, E.J., Feria-Dominguez, J.M. \& Martin-Marin, J.L. (2009). Comparative analysis of operational risk approaches within Basel regulatory frame-work: case study of Spanish Saving Bank. Journal of Financial Management and Analysis, 22(1):1-15.

12. Jobst, A.A. (2007). It's all in the data - consistent operational risk measurement and regulation. Journal of Financial Regulation and Compliance, 15(4):423-449.

13. Lubbe, J., \& Snyman, F. (2009). Advanced Measurement Approach for Banks. www.statssa.gov.za/isi2009/ScientificProgramme/IPMS/0256.pdf

14. Matis, E. (2009). Operational banking risk management - research performed at the Romanian Commercial Bank. Annals of the University of Oradea, Economic Science Series, 18(3):593-597.

15. Moosa, I.A. (2008). A critique of the advanced measurement approach to regulatory capital against operational risk. Journal of Banking regulation, 9(3):151-164.

16. Teply, P., Sekhri, V. \& Chalupka, R. (2010). Modelling capital requirements for operational risk in emerging markets' banks. Decision, 37(1):83-100.

17. Van Niekerk, A., Levin, M.M. \& Geldenhuys, D.J. (2011) Risk is socially defined: A Tanzanian study. Unpublished.

18. Young, J. (2006), Operational Risk Management: A practical application of a qualitative approach. Van Schaik Publishers, Pretoria, RSA. 